\title{
Microstructural evolution and bonding characteristic in multi-layer laser cladding of NiCoCr alloy on compacted graphite cast...
}

Article in Journal of Materials Processing Technology · February 2016

DOI: 10.1016/j.jmatprotec.2016.02.001

\section{CITATIONS}

5

6 authors, including:

Hao Liu

China University of Mining Technology

6 PUBLICATIONS 16 CITATIONS

SEE PROFILE

\section{Gang Yu}

Chinese Academy of Sciences

42 PUBLICATIONS 585 CITATIONS

SEE PROFILE
READS

250
Jingbin $\mathrm{HaO}$

China University of Mining Technology

23 PUBLICATIONS 41 CITATIONS

SEE PROFILE

Xiuli He

Chinese Academy of Sciences

45 PUBLICATIONS 611 CITATIONS

SEE PROFILE 


\title{
Microstructural evolution and bonding characteristic in multi-layer laser cladding of NiCoCr alloy on compacted graphite cast iron
}

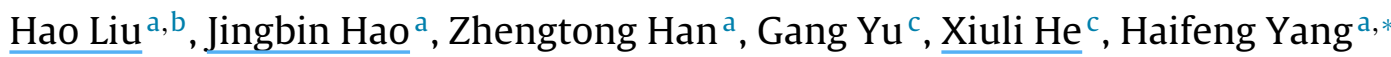 \\ a School of Mechanical and Electrical Engineering, China University of Mining and Technology, Xuzhou 221116, China \\ b Jiangsu Key Laboratory of Mine Mechanical and Electrical Equipment, China University of Mining E Technology, Xuzhou 221116, China \\ c Key Laboratory of Mechanics in Advanced Manufacturing, Institute of Mechanics, Chinese Academy of Sciences, Beijing 100190, China
}

\section{A R T I C L E I N F O}

\section{Article history:}

Received 25 August 2015

Received in revised form

20 December 2015

Accepted 1 February 2016

Available online 3 February 2016

\section{Keywords:}

Multi-layer laser cladding

Cast iron

Bonding interface

Microstructural evolution

Micro-hardness

\begin{abstract}
A B S T R A C T
Laser cladding of NiCoCr alloy powder on cast iron was performed with a $1 \mathrm{~kW} \mathrm{Nd:YAG} \mathrm{continuous}$ laser. Despite numerous advantages, one of the most critical issues is the formation of martensite and a brittle layer in the vicinity of the bonding interface due to the inherent rapid cooling, which might result in cracking nearby and a decrease in bonding strength. The objective of this research is to produce well bonded NiCrCo alloy coating that is free of pores and cracks on cast iron without preheating the whole substrate. Considering the poor weldability of cast iron, the strategy of reciprocated deposition, namely multi-layer laser cladding, was applied. The microstructural evolution of the multi-layer coating on the cast iron was investigated with the emphasis on the variation of the bonding zone. The results showed that $\mathrm{NiCoCr}$ coatings with different layers consisted of fine solid solution dendrites surrounded by an inter-dendritic network of precipitates. The multi-layer clad coating had a gradual distribution of elements, which was different from that in the single layer coating. The martensite near the bonding interface was transformed into tempered sorbite under the thermal influence of multi-layer deposition, leading to a decrease in the high micro-hardness zone width. A bending test confirmed that the bonding brittleness was reduced and the mechanical properties were improved through the use of the multi-layer laser cladding approach.
\end{abstract}

(C) 2016 Elsevier B.V. All rights reserved.

\section{Introduction}

Cast iron is an Fe-C alloy which is widely used in the manufacture of various components with complex shapes and cavities due to its good castability, excellent machinability, low cost, and excellent vibration damping. A large number of these components, such as pistons and cylinders used in the automotive industry, suffer from severe cyclic thermal and mechanical loads simultaneously produced by localised intense fire, explosion pressure, or clamping of the components. Unfortunately, the thermal fatigue resistance of cast iron is undesirable owing to the presence of a high percentage of free graphite, as well as the interfaces between the free graphite and metallic matrix. Therefore, cyclic thermal loading usually results in cracking on the surface of cast iron, leading to failures. It is essential to modify the surface properties of cast iron for higher reliability and a longer service life.

\footnotetext{
* Corresponding author.

E-mail address: leonardo20081h@163.com (H. Yang).
}

Laser cladding is an advanced surface modification method used to produce metallurgical bonded, high-performance, fully dense coatings on metallic substrates with specific advantages over conventional surface modification processes. These include: fine microstructure, a narrow heat-affected zone, low distortion, and ease of automation. In laser cladding, a high-power-density laser beam is used to create a melt pool on a substrate. Meanwhile, the additive powder material is injected toward the melt pool by an inert gas. The melt pool solidifies and a deposited layer with special performance is produced after the laser beam moves away. A laser coating of up to $2 \mathrm{~mm}$ could be deposited by overlapping successive tracks (Smurov et al., 2013; El Cheikh et al., 2012a), providing a way to protect the base metal from thermal shock.

Several experiments and simulations have been carried out to investigate laser processing of cast iron surfaces. Benyounis et al. (2005) investigated the surface melting of nodular cast iron by Nd-YAG laser: it was found that the laser-melted zone was composed of finer dendrites of retained austenite surrounded by a continuous network of cementite and some acicular martensite. Alabeedi et al. (2009) performed laser surface melting of nodular graphite cast iron using a $3 \mathrm{~kW} \mathrm{CW} \mathrm{CO} 2$ laser. They found a simi- 


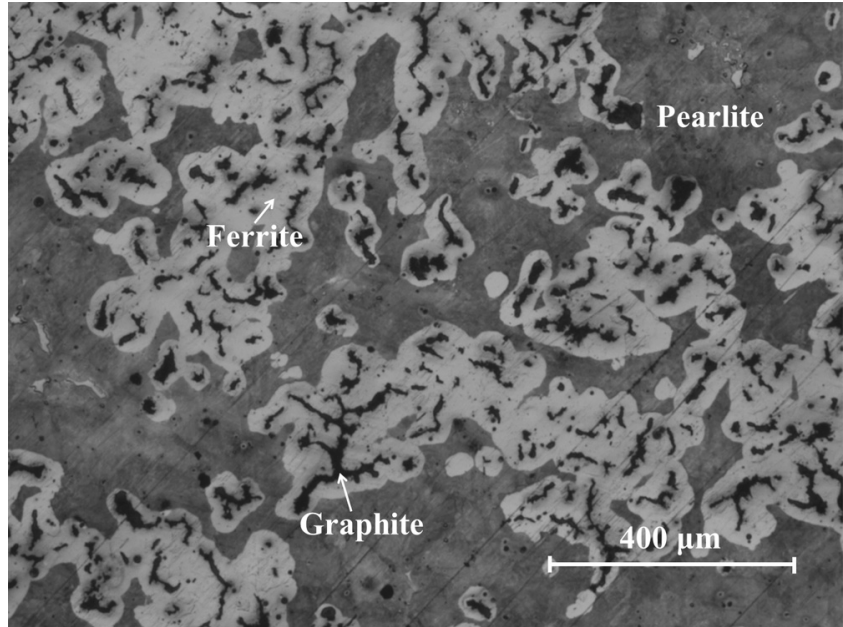

Fig. 1. Microstructure of compacted graphite cast iron.

lar microstructure with high hardness. Sun et al. (2011) produced wear-resistant layers on nodular cast iron rolls with $\mathrm{C}-\mathrm{B}-\mathrm{W}-\mathrm{Cr}$ powder using laser surface alloying techniques. Their research indicated that the bonding area was different from the top part of the alloyed layer. In addition to the typical dendrite structure bonded with the substrate, a coral-like structure was detected in the bonding area. Yan et al. (2010) reported that some acicular martensite and ledeburite, characterised by high hardness and poor toughness, were formed at the interface and in random locations on the laser clad layer on a ductile iron sample. Similar results were found by Arabi Jeshvaghani et al. (2014): they found eutectic ledeburite and a martensite microstructure in the partial melted zone (PMZ) and only a martensitic microstructure in heat affected zone (HAZ). Ocelík et al. (2007) used a $2 \mathrm{~kW}$ continuous Nd:YAG laser to fabricate Co-based coatings on compacted graphite and gray cast iron substrates, and established empirical relationships between the process parameters (i.e. laser power, powder feeding rate, and scanning speed) and the geometric features of its single-track. It was found that crack propagated from the bonding interface and layer interior when thicker coatings were deposited on a stiff substrate as a consequence of internal stresses. Lestan et al. (2013) used three different powders for laser deposition of cast iron to investigate the microstructure and cracking of the coating. Many cracks originating from the bonding zone were observed. Xu et al. (2014) established two numerical models which included a macro-laser cladding model, and a micro-graphite model to analyse the stress variation of the graphite area of grey cast iron, and demonstrated that the graphite tip was a hazardous area for microcrack initiation due to tensile stress concentrations thereat. Yan et al. (2014) studied the process of laser cladding a NiCuFeBSi alloy layer on grey cast iron. The formation of martensite in the HAZ was interpreted on the basis of carbon diffusion and cooling rate in their research.

Preheating the substrate has been suggested as a way of reducing the thermal stress, as well as cracking susceptibility, in the laser cladding process. Jendrzejewski et al. (2006) concluded that the calculated strain and stress were reduced in cases using preheating. Crack-free layers were fabricated with a substrate preheated to a temperature of $873 \mathrm{~K}$; Lin et al. (2014) proved that graphite nodules, where microcracks usually were initiated, were dissolved during preheating. Hence, the number of microcracks in the bonding zone decreased. In the preheating process, the base metal must be put in a furnace to heat it to a definite temperature, and then that is maintained for a certain time. This method is accompanied by substantial energy consumption, poor production efficiency, an

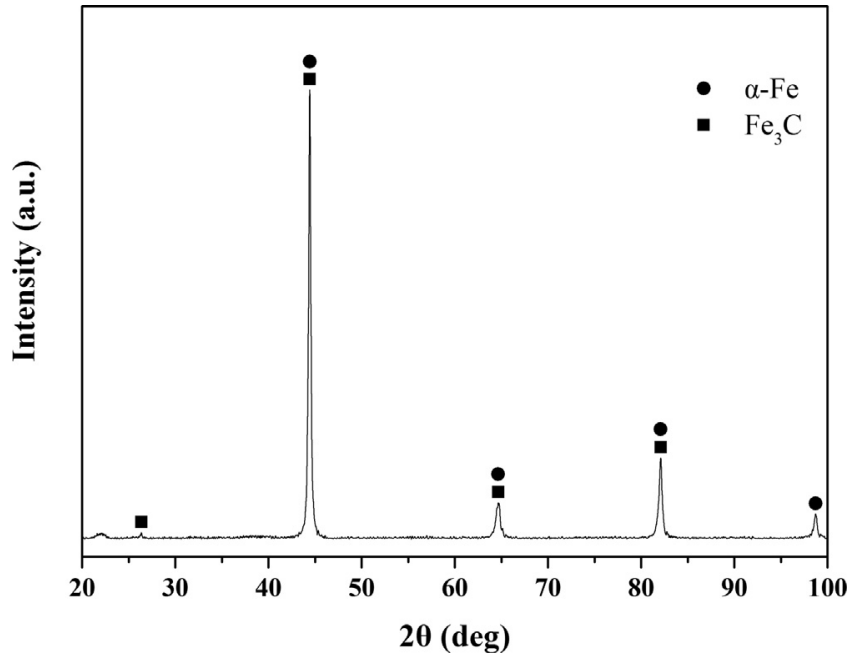

Fig. 2. XRD pattern of compacted graphite cast iron.

undesirable working environment, etc. Besides, this method could not be used on work-pieces that are too large to put in a furnace.

It could be concluded, from the aforementioned research, that there are some difficulties and issues arising from the use of laser cladding processes on cast iron; because large amounts of free carbon, in the form of various kinds of graphite, are present, carbon dioxide could be produced in the melt pool when the laser beam radiates to the surface of cast iron, which easily leads to the formation of pores. Another issue is connected with the high laser absorption of the graphite compared with that of the metal matrix. The laser absorption difference makes the graphite act as if it were many heat sources distributed within the cast iron. Therefore, nonhomogeneous thermal, and stress, fields may be created. The major issue is involved with the poor weldablity of cast iron. The majority of researchers have revealed that the phases of martensite and ledeburite were formed at the bonding zone due to the high cooling rate. These phases have high hardness but poor plasticity and toughness, resulting in brittleness of the bonding zone between the substrate and the clad layer. Meanwhile, the phase transformation of austenite to martensite may develop microcracking at the bonding interface, due to the specific volume variation and the deformation constraints at the grain boundary.

The objective of this study is to produce well bonded $\mathrm{NiCrCo}$ alloy layers on cast iron, without preheating the whole substrate, using a Nd:YAG laser. Taking the material properties of cast iron into account, the strategy of reciprocated deposition, namely multilayer laser cladding, is applied. The microstructural evolution in the clad layer, as well as the bonding zone of the cast iron, is investigated. The hardness and bending characteristics of cast iron coated by $\mathrm{NiCrCo}$ alloy are also examined.

\section{Materials and experimental design}

\subsection{Materials and laser equipment}

Compacted graphite cast iron (CGI) cut from a cylinder measuring $120 \mathrm{~mm} \times 60 \mathrm{~mm} \times 30 \mathrm{~mm}$ was used as a substrate. The main chemical composition of CGI included (in wt.\%): 3.6C, $2.7 \mathrm{Si}, 0.2$ $\mathrm{Mn},<0.05 \mathrm{P},<0.02 \mathrm{~S}$, and the remainder Fe. The microstructure and XRD pattern of CGI were shown in Fig. 1 and Fig. 2, respectively. The microstructure of CGI was a large amount of graphite surrounded by a ferrite-pearlite matrix. The grain size of ferrite was mainly in the range of 100-300 $\mu \mathrm{m}$. The majority of the graphite was vermicular, while the rest was nodular. The deposited material was a Ni-based alloy with a particle size distribution of $40-150 \mu \mathrm{m}(-100 /+325$ 
(a)

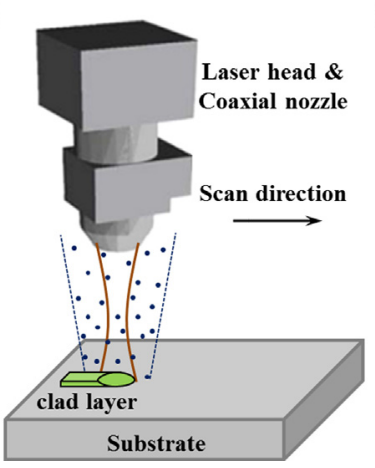

(b)

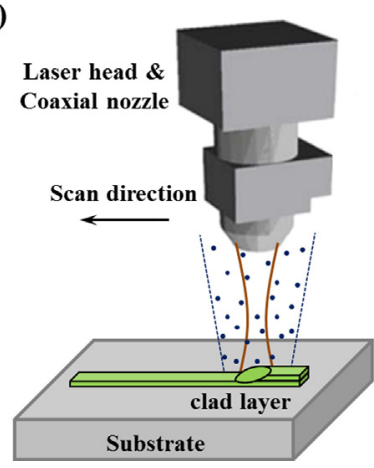

Fig. 3. Schematic diagram of the multi-layer laser cladding process.

sieve size), whose composition was as follows: (in wt.\%): 2.6Co, $18.6 \mathrm{Cr}, 3.4 \mathrm{Al}$, and the remainder $\mathrm{Ni}$. The cladding materials were selected from the perspective of application performances and processing properties. $\mathrm{NiCoCr}$ is a kind of the Ni-based superalloy, which has a stable microstructure, strong oxidation and corrosion resistance. As the cladding material, the main element $(\mathrm{Ni})$ in it could form an infinite solid solution with the main element (Fe) in the matrix material. This indicated that the cladding materials had favourable compatibility. The addition of Co could improve the strength and creep resistance of coatings at high temperature, while an appropriate amount of $\mathrm{Cr}$ could increase the oxidation and corrosion resistance. Since the cladding materials was consistent with the matrix material in terms of thermos-physical parameters, the processing properties of the cladding were desirable.
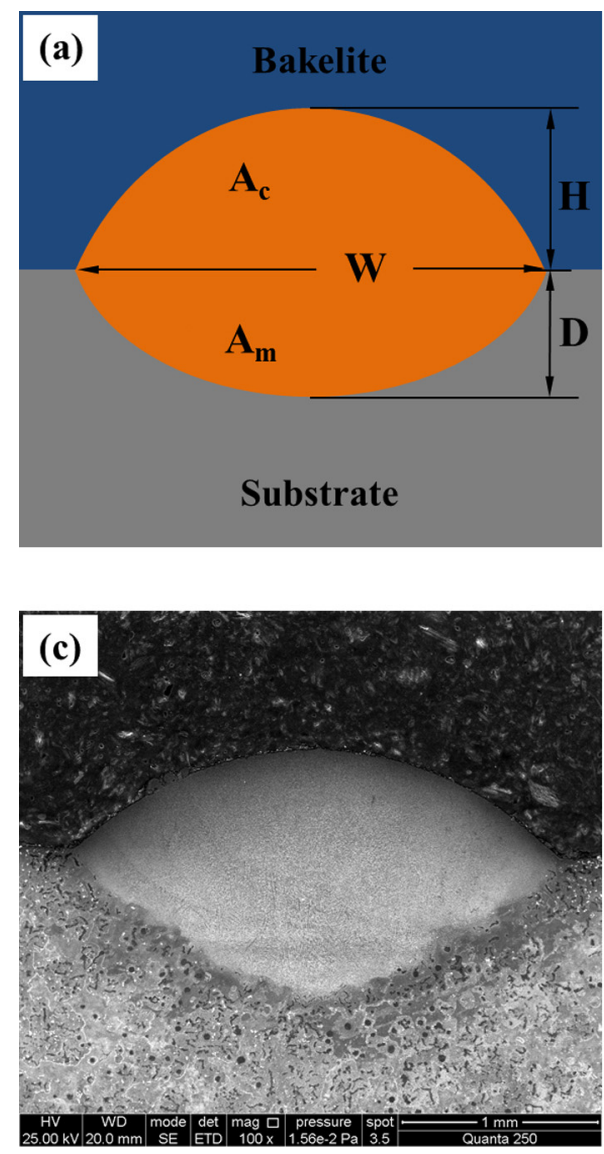

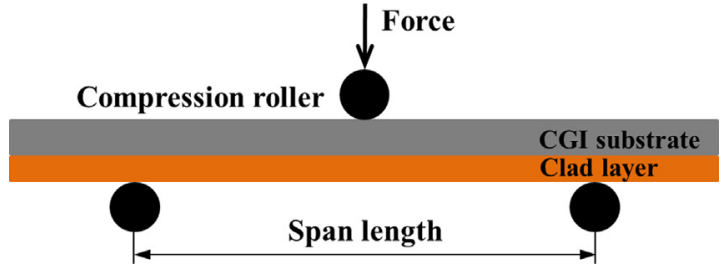

Fig. 4. Three-point bending test.

Before the experiment, the substrates were rubbed with abrasive paper and cleaned with acetone to remove all undesirable contamination, and the powder was dried to ensure its flowability.

Laser cladding experiments on CGI were conducted with a $1 \mathrm{~kW}$ continuous wave Nd:YAG laser at a wavelength of $1.064 \mu \mathrm{m}$. The energy was transmitted to a laser head by a $100 \mu \mathrm{m}$ diameter optical fibre, and then passed through a $200 \mathrm{~mm}$ focal length collimator and $150 \mathrm{~mm}$ focusing lens in the laser head. A circular laser beam spot area on substrate was obtained when the laser was delivered out of focus. A five-axis CNC Table installed with this laser head was used to provide relative motion between the laser head and substrates. The powder, together with the carrier gas, was delivered to the melt pool generated on the substrate surface by a coaxial powder feeder, which was mounted on the laser head. Argon was applied to carry powder particles and to protect the melt region from oxidation. All the samples were deposited by the reciprocating motion of the laser head.
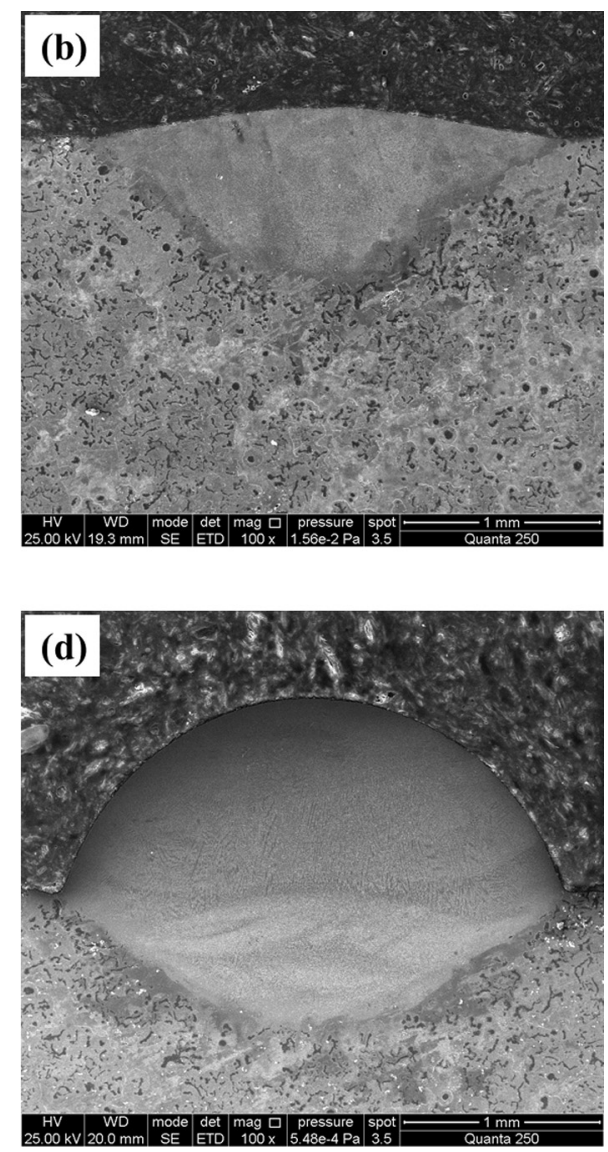

Fig. 5. Typical cross-section of the coating (a) showing its main geometrical characteristics under the condition of (b) one layer, (c) three layers, and (d) six layers. 
Table 1

Processing parameters used in laser cladding experiments.

\begin{tabular}{|c|c|c|c|c|}
\hline Laser power(W) & powder feed rate $(\mathrm{g} / \mathrm{min})$ & Scan velocity $(\mathrm{mm} / \mathrm{s})$ & Spot size $(\mathrm{mm})$ & Shielding gas flow rate $(\mathrm{L} / \mathrm{min})$ \\
\hline 900 & 4.3 & 6 & 2.0 & 5 \\
\hline
\end{tabular}

Table 2

The geometrical parameters and dilutions in cross-section of the coating.

\begin{tabular}{|c|c|c|c|c|c|c|}
\hline Sample & L1 & $\mathrm{L} 2$ & L3 & L4 & L5 & L6 \\
\hline Width/mm & 2.279 & 2.386 & 2.404 & 2.412 & 2.601 & 2.627 \\
\hline Layer height/mm & 0.235 & 0.339 & 0.527 & 0.697 & 0.860 & 0.961 \\
\hline Melt depth/mm & 0.618 & 0.782 & 0.732 & 0.751 & 0.744 & 0.723 \\
\hline $\mathrm{A}_{\mathrm{c}} / \mathrm{mm}^{2}$ & 0.390 & 0.506 & 0.890 & 1.196 & 1.580 & 1.876 \\
\hline $\mathrm{A}_{\mathrm{m}} / \mathrm{mm}^{2}$ & 0.816 & 1.083 & 1.041 & 1.120 & 1.206 & 1.076 \\
\hline Dilution/\% & 67.7 & 68.2 & 53.9 & 48.4 & 43.3 & 36.4 \\
\hline
\end{tabular}

\subsection{Experimental design}

The approach of superimposed scanning pattern with relatively low powder feed rate was employed in this laser cladding process (see Fig. 3). When the laser cladding process started, the laser beam and coaxial powder feeder travelled along the designed path and the powder was delivered into the melt pool simultaneously. When one layer was deposited, the laser beam and coaxial powder feeder travelled in the opposite direction along the path. Then a new layer was deposited on the previous one. After the deposition process had finished, the workpiece was cooled in air. In each experiment, the processing parameters were kept constant.

Laser power $(P)$, powder feed rate $(F)$, and scan velocity $(V)$ played a major role in the quality of the clad layer. Before this study, the process window for a fine laser clad layer has been explored using the gradient technique proposed by Ocelík et al. (2007). The optimised processing parameters (see Table 1) have been used to achieve a defect-free layer on cast iron using a reciprocated scan pattern in this study. To investigate the microstructural evolution in the clad layer, as well as in the bonding zone during the process, the coatings were deposited in one to six layers, respectively. The corresponding samples were labelled as L1-L6, respectively.

\subsection{Microstructural analysis}

Cross-sections were extracted from each sample and mounted in bakelite, followed by mechanical polishing. The geometrical characteristics of the cross-section were measured from an image taken by optical microscopy (OM). These specimens were chemically etched by immersion for several minutes in aqua regia. Then microstructural examination of the clad bead was performed using a scanning electron microscope (SEM) equipped with an energy dispersive X-ray spectrometer (EDS). After this, the specimens were ground and polished again to remove the previously etched surface. They were then corroded with nital (96\% alcohol with $4 \%$ nitric acid) for the microstructural examination of the bonding zone of each specimen under optical microscopy. The micro-hardness of the cross-section from the layer surface to the CGI substrate was measured using a Vickers hardness tester HXD-1000 with a load of $100 \mathrm{~g}$ and a dwell time of $15 \mathrm{~s}$. The measurements were made along the middle of the clad cross-sections. The spacing between successive points was as small as $50 \mu \mathrm{m}$ to ensure the detection of micro-hardness variations at the bonding interface.

\subsection{Bending test}

A three-point bending test was carried out to investigate the bonding characteristic and mechanical property of the clad layer. The design dimensions of specimen were $60 \mathrm{~mm} \times 10 \mathrm{~mm} \times 2 \mathrm{~mm}$. An uncoated specimen, marked S1, was tested for reference. The other specimens were produced by overlapping method with an overlapping ratio of $30 \%$. The specimen created in a single clad layer was labelled S2, and that created by the multi-layer depositon was labelled S3. After the coatings were deposited, the specimens were cut to their design dimensions and a uniform layer depth of $0.8 \mathrm{~mm}$ was ensured. All the surfaces of the specimens were ground with abrasive paper. A universal material testing machine RG3000A was used for testing with a $10 \mathrm{~mm}$ compression roller, a $40 \mathrm{~mm}$ span, and a cross-head speed of $1.0 \mathrm{~mm} / \mathrm{min}$. In the view of good compressive properties of CGI, the side of CGI material in the specimen was placed upwards, in contact with the compression roller (Fig. 4).

\section{Results and discussion}

\subsection{Geometrical characteristics and dilution}

The geometrical characteristics of the cross-section could reflect the quality of the coating. In each cross-section, the contour lines of the coating surface were arcuate (see Fig. 5). On the basis of this circular geometry, it was evident that surface tension forces were dominant in the melt pool (see also, El Cheikh et al. (2012b)). The width $W$, coating height $H$, melt depth $D$, clad area $A_{c}$, and melt area $A_{\mathrm{m}}$, for each clad layer were measured (see Table 2). The clad layer widths ranged from $2.279 \mathrm{~mm}$ to $2.627 \mathrm{~mm}$, and were slightly greater than the laser beam diameter. The height and the melt depth of the first deposited layer was $0.235 \mathrm{~mm}$ and $0.618 \mathrm{~mm}$, respectively. The mean thickness of the each subsequent layer was about $0.145 \mathrm{~mm}$. When the number of deposited layers increased, the coating height increased linearly and the width increased slightly. It is worth noting that the melt depth remained almost constant after the second layer was deposited, indicating that the CGI substrate beneath the bonding interface might no longer melt.

The dilution has been defined to represent the extent of the impact of substrate composition on the clad layer and it could be calculated by the geometrical characteristics as:

$\eta=\frac{A_{\mathrm{m}}}{A_{\mathrm{c}}+A_{\mathrm{m}}}$

The calculated dilutions are also listed in Table 2: the dilution of sample L1 was $67.7 \%$. This indicated that the melt of CGI material consumed most of the absorbed laser power and the composition melt forming the substrate should dominate in the coating. The dilution declined from $67.7 \%$ of that of sample $\mathrm{L} 1$ to $36.4 \%$ of that of sample $\mathrm{L} 6$.

The microstructure of multi-layer coating in cross-section obtained by OM is shown in Fig. 6. The boundaries of the adjacent depositon layer (re-melting lines) were detected, indicating that only the top region of the coating, rather than the whole region of the coating, was melt by each deposition process. The depth of bot- 

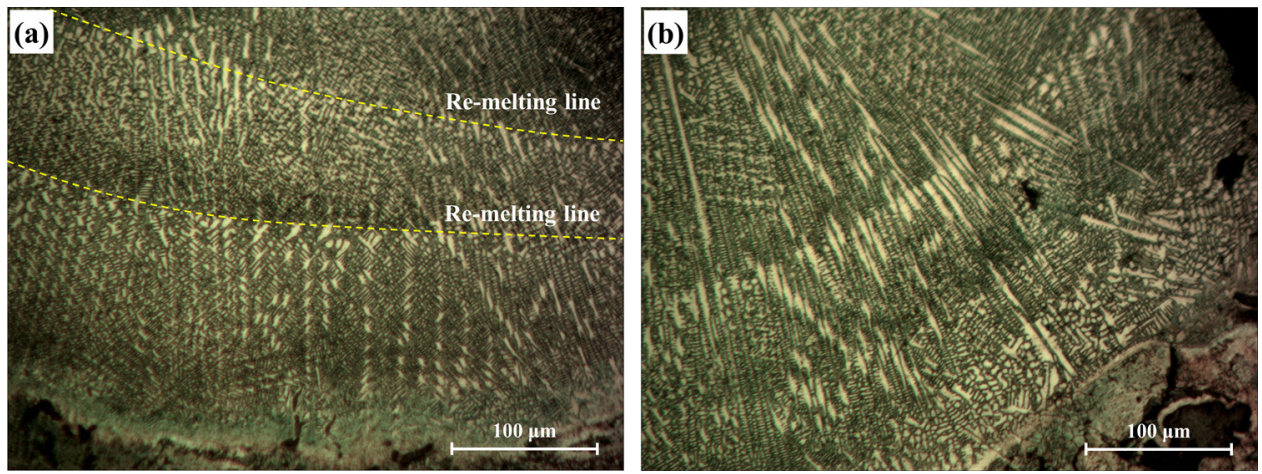

Fig. 6. The microstructure of multi-layer coating (sample L4) in the vicinity of the bonding interface showing (a) the re-melting line and (b) the epitaxial growth.
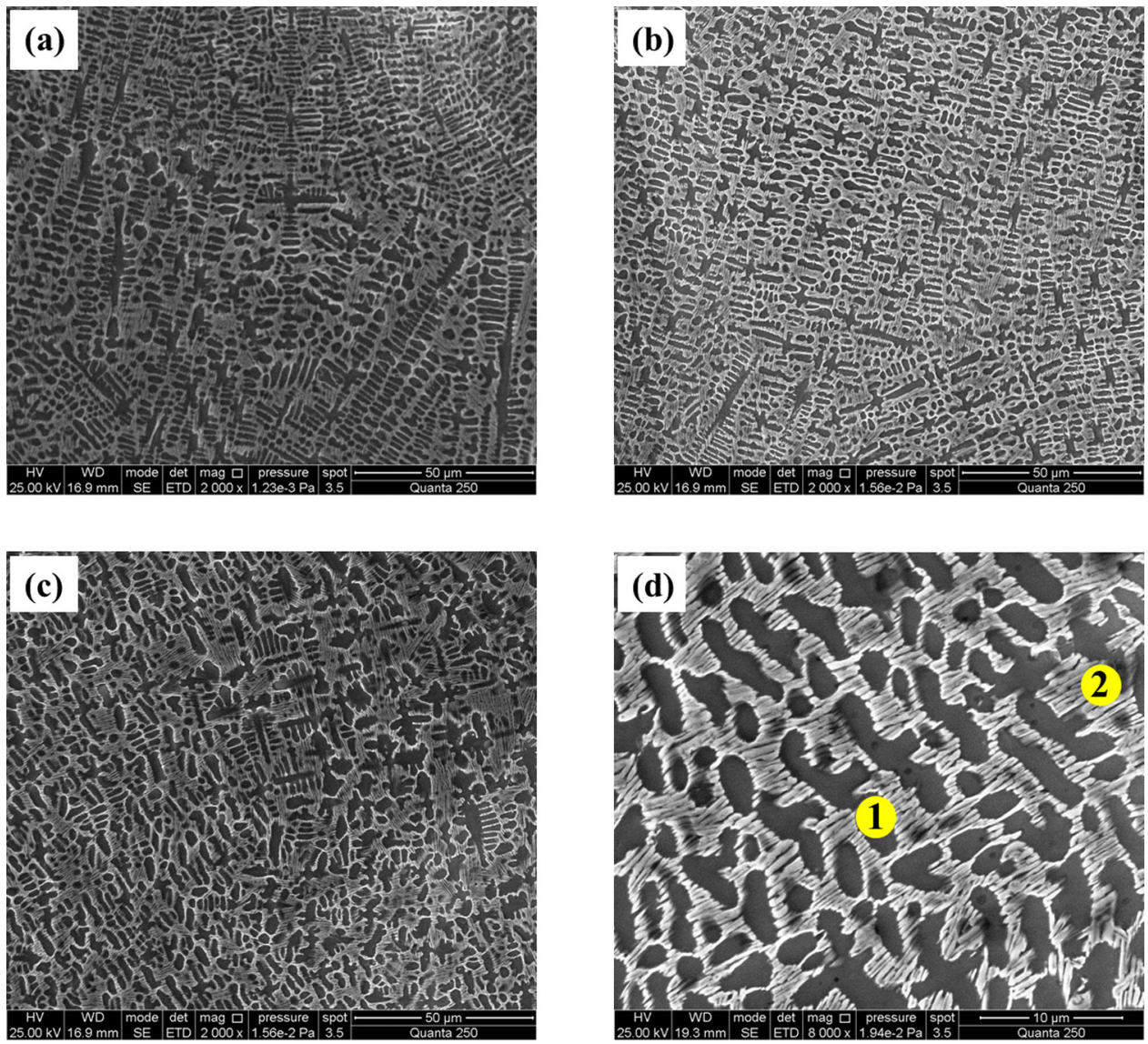

Fig. 7. The microstructure of the clad layer in the cross-section of sample L1, (a) bottom region, (b) interior region, (c) top region, (d) magnified view of interior region.

tom region that was not melt by latest depositon increased with the increasing depositon layer.

\subsection{Microstructure in the coating}

The microstructure of a typical single layer coating (sample L1) in the cross-section is shown in Fig. 7: Fig. 7(a-c) correspond to the top region, interior region, and bottom region of the clad layer, respectively, and Fig. 7(d) shows a magnified view of Fig. 7(b). As can be seen in Fig. 7, the coating exhibited fine dendrites surrounded by an inter-dendritic network of precipitates. Similar microstructure was observed in the laser surface melting and laser surface alloying of nodular cast iron by Benyounis et al. (2005) and Sun et al. (2011), respectively. The microstructure at the bottom of the coating was mainly composed of columnar dendrites with sec- ondary arms. The mean primary dendrite arm spacing was $9.5 \mu \mathrm{m}$, and the secondary dendrite arm spacing (SDAS) was about $0.5 \mu \mathrm{m}$. The experimentally determined relationship between SDAS and cooling rate for a series of alloy systems is (Zheng et al., 2008):

$\mathrm{SDAS}=A(\dot{T})^{-n}$

where $\dot{T}$ is cooling rate $(\mathrm{K} / \mathrm{s})$, and $A$ and $n$ are constants depending on the particular alloy system being studied. As for Fe alloy, the values of $A$ and $n$ are 100 and 0.35 . Accordingly, the cooling rate, when the bottom of melt pool solidified, could reach $3.8 \times 10^{6} \mathrm{~K} / \mathrm{s}$, which is much more higher than that when casting (about $10 \mathrm{~K} / \mathrm{s}$ ). Fig. 7(b) and (c) show dendritic microstructure at the interior region and top region of clad layer. A small amount of equiaxial dendrite was detected among the columnar dendrites. The morphology transition is due to the difference in the $G / R$ ratio ( $G$ represents the 

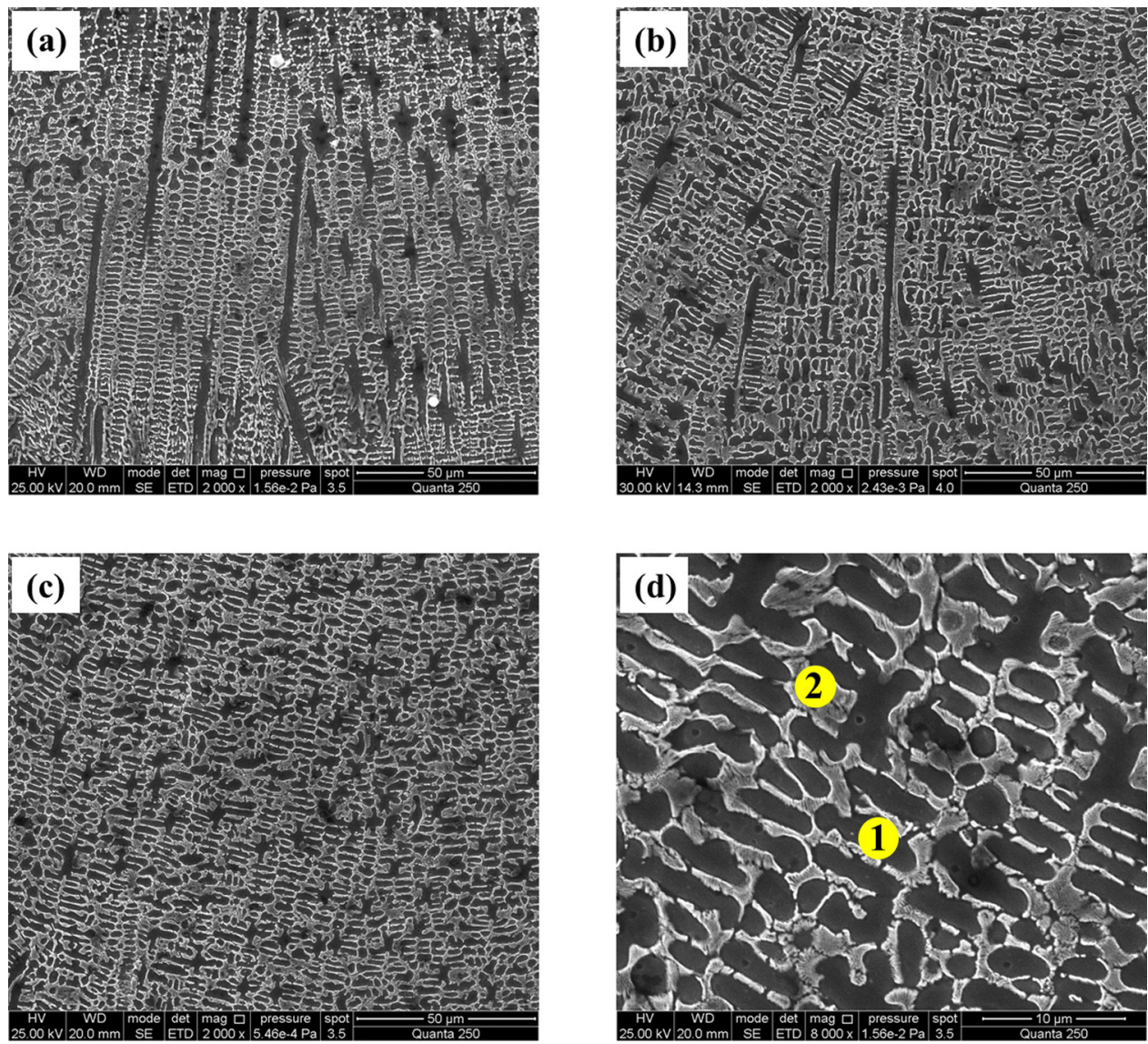

Fig. 8. The microstructure of the clad layer in the cross-section of sample L3, (a) bottom region, (b) interior region, (c) top region, (d) magnified view of interior region.

temperature gradient, and $R$ represents the solidification rate) at different locations during solidification. The $G / R$ ratio at the bottom, in the vicinity of the bonding interface, is extremely high, giving rise to columnar dendritic growth. As the solidification front moves towards the surface, the ratio of $G / R$ decreases. Therefore, the equiaxial dendritic growth occurred, reuslting in the equiaxed morphology in micostructure. Additionally, the primary arm of columnar dendrite was much shorter than the dendrite in the bottom region, owning to the section effect and the change of the growth direction. Precipitates were lamellar in shape at the interdendritic zone, as seen in Fig. 7(d). Examination of microstructure at high magnification did not show any distinctive martensitic features.

The microstructural evolution of the laser clad coating with three layers (sample L3) is shown in Fig. 8. The dendritic structure was also evident in the cross-section through the coating (see Fig. $8(\mathrm{a}-\mathrm{c})$ ). The columnar dendrites showed fairly uniform growth directions in the bottom region (Fig. 8(a)), and extended to the interior region of the coating (Fig. 8(b)). The equiaxial dendrites only appeared at the top region (Fig. 8(c)). In the multi-layer cladding, the solidification of each subsequent layer should begin by epitaxial growth without nucleation, as is shown in Fig. 6. According to the theory of Bezencon et al. (2003), the crystallographic structure and dendrite orientation of the pre-deposited layer were reproduced. Thus the directionally solidified columnar crystal was obtained by the epitaixal growth, which has been found to possess high thermal stability, high-temperature strength, and high thermal fatigue resistance because of the removal of transverse grain boundaries which are perpendicular to stress direction. It could also be seen from Fig. 8(d) that most of the precipitates distributed in the interdendritic zone were small and acicular, rather than lamellar.
Fig. 9 shows the microstructural characteristics of the laser clad coating with six layers (sample L6). The evolution of microstructure was similar to that in the coating with three layers. In addition, Fig. 9(b) shows that there were relatively coarser dendrites at the boundary of adjacent layers, indicating the complicated dendrite size variation in the multi-layer coating. This can be explained by the thermal cycles imposed during the multi-layer cladding process. When a new layer was being deposited, the top region material re-melted under the irradiation of the laser beam. The pre-deposited material under the re-melt interface underwent a high temperature change, instead of re-melting, which gave the dendrites in this zone a period of time in which to grow. The morphology of the precipitates was the same as it was in the coating with three layers. Yet the amount of the precipitates was slightly reduced as is seen from Fig. 9(c) and (d).

The chemical composition of the spots in Figs. 7 (d), 8 (d), and 9 (d) is listed in Table 3. The sensitivity of EDS is too poor to detect light elements such as carbon, so that results are presented regardless of percentage of carbon. The dendrites (Spot 1) were mainly composed of $\mathrm{Fe}, \mathrm{Ni}$, and $\mathrm{Cr}$. Combining Figs. 7-9, the EDS results, and the XRD patterns(Fig. 10), it can be inferred that the primary dendrite was a Fe-Ni solid solution with an fcc structure. A few $\mathrm{Cr}$, $\mathrm{Co}, \mathrm{Al}, \mathrm{Si}$, and $\mathrm{C}$ elements were dissolved in the primary dendrite as a consequence of the high cooling rate. As a result of the high $\mathrm{Fe}$ content, the lamellar precipitate in the single layer coating (sample L1) was $\mathrm{Fe}_{3} \mathrm{C}$. The content of $\mathrm{Cr}$ in spot 2 increased significantly in both samples $\mathrm{L} 3$ and L6. The small, acicular precipitate was believed to be $\mathrm{Cr}_{3} \mathrm{C}_{7}$ and $\mathrm{Cr}_{23} \mathrm{C}_{6}$ according to Sun et al. (2011), who demonstrated that $\mathrm{Cr}_{3} \mathrm{C}_{7}$ and $\mathrm{Cr}_{23} \mathrm{C}_{6}$ were more stable than $\mathrm{Cr}_{3} \mathrm{C}_{2}$ in the reaction of $\mathrm{Cr}$ and $\mathrm{C}$ from the view of the Gibbs formation energy. 

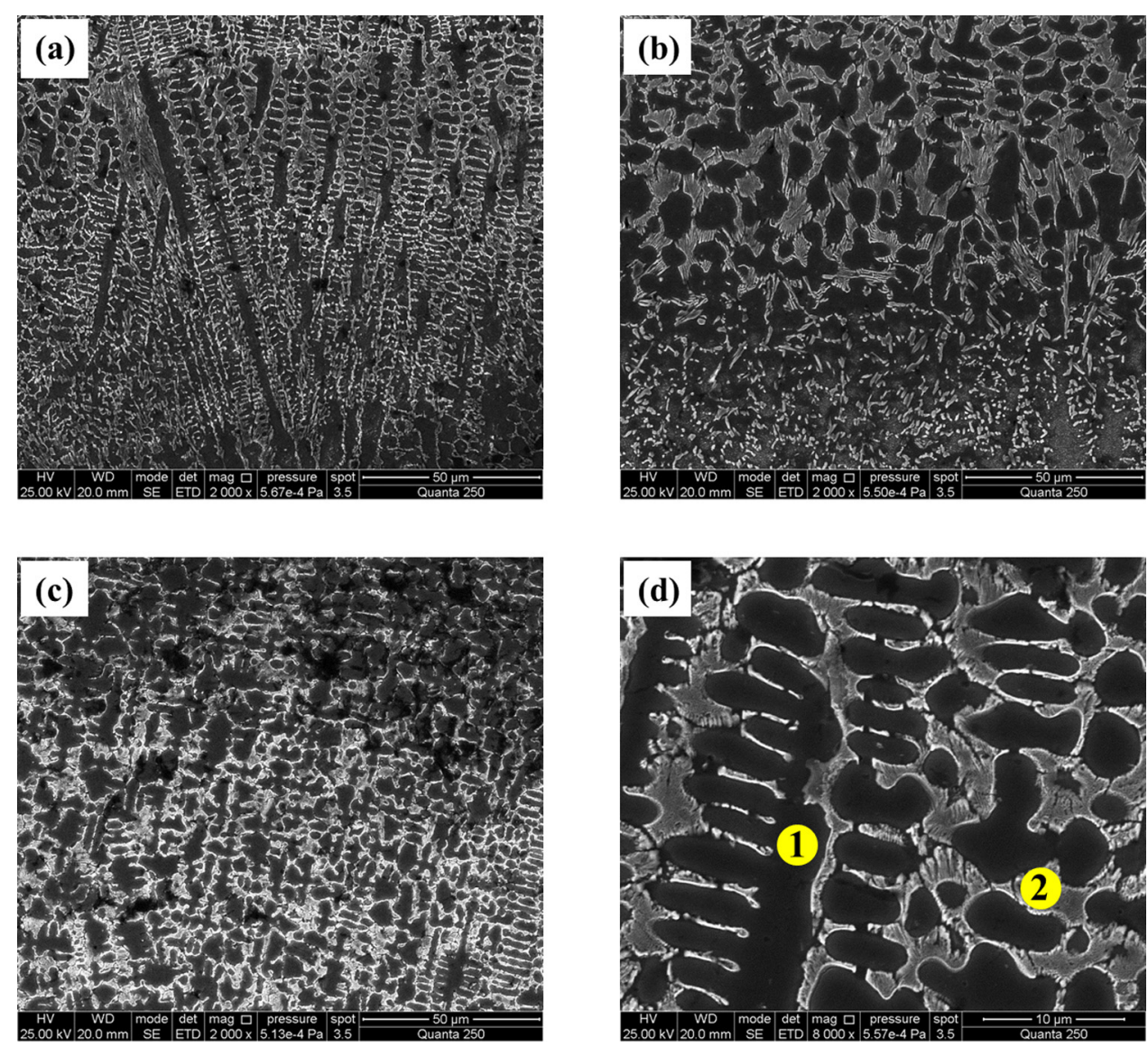

Fig. 9. The microstructure of the clad-layer in the cross-section of sample L6, (a) bottom region, (b) interior region, (c) top region, (d) magnified view of interior region.

Table 3

Chemical composition of spots in Figs. 7(d), 8(d), and 9(d) (wt\%).

\begin{tabular}{|c|c|c|c|c|c|c|c|}
\hline Sample & Spectrum & $\mathrm{Fe}$ & $\mathrm{Ni}$ & $\mathrm{Cr}$ & Co & $\mathrm{Al}$ & $\mathrm{Si}$ \\
\hline \multirow[t]{2}{*}{ L1 } & 1 & 73.71 & 18.09 & 3.34 & 2.61 & 0.63 & 1.62 \\
\hline & 2 & 77.96 & 13.04 & 5.41 & 2.32 & 0.26 & 1.00 \\
\hline \multirow[t]{2}{*}{ L3 } & 1 & 49.78 & 35.89 & 8.61 & 2.85 & 1.11 & 1.77 \\
\hline & 2 & 52.84 & 28.52 & 14.22 & 2.76 & 0.56 & 1.10 \\
\hline \multirow[t]{2}{*}{ L6 } & 1 & 29.62 & 56.11 & 8.92 & 2.98 & 1.32 & 1.05 \\
\hline & 2 & 30.19 & 48.09 & 16.65 & 2.9 & 1.17 & 1.11 \\
\hline
\end{tabular}

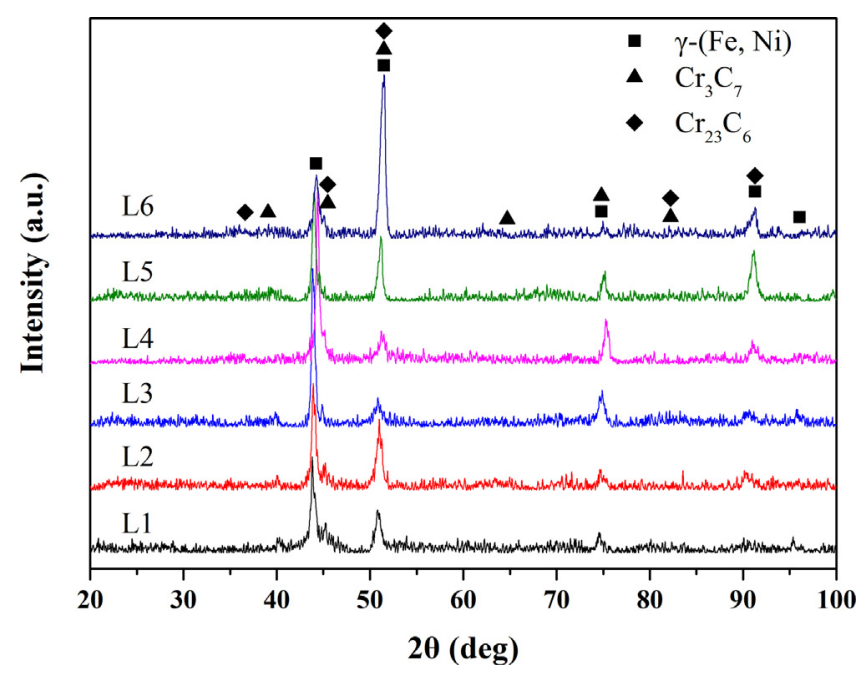

Fig. 10. XRD patterns of the coatings deposited by one to six layers.
Fig. 11 shows the EDS line analysis results from the laser clad coating from the top to the bottom for $\mathrm{Fe}, \mathrm{Ni}, \mathrm{Co}, \mathrm{Cr}, \mathrm{Si}$, and $\mathrm{Al}$. It can be found from Fig. 11(a) that the distribution of these alloy elements was approximately homogenous in single layer coatings (sample L1), due to vigorous convection in the melt pool caused by rapid heating of the laser beam. The clad powder material did not contain any elemental Fe. Therefore, the elemental Fe in the coating, the content of which in the single layer coating was higher than any of other element, came from melting of the CGI substrate.

In the multi-layer coating, elements, such as $\mathrm{Ni}$ and $\mathrm{Cr}$, were inhomogeneous along the depth direction, as illustrated in Fig. 11(b) and (c). The Fe content decreased and $\mathrm{Ni}, \mathrm{Co}$, and $\mathrm{Cr}$, which came from the clad material, contents increased from the bottom to the top of the coating. This inhomogeneous distribution was attribute to partial re-melting of the pre-deposited layer shown in Fig. 5, and represented the dilution variation whthin the multilayer coating. The dilution could be expressed in macro-level and micro-level: the dilution calculated by the geometrical characteristics of cross-section (Table 2) was a mean value, and represented the dilution effect of the matrix components on the cladding materials in general. The dilution expressed by the elemental distribution 
(a)
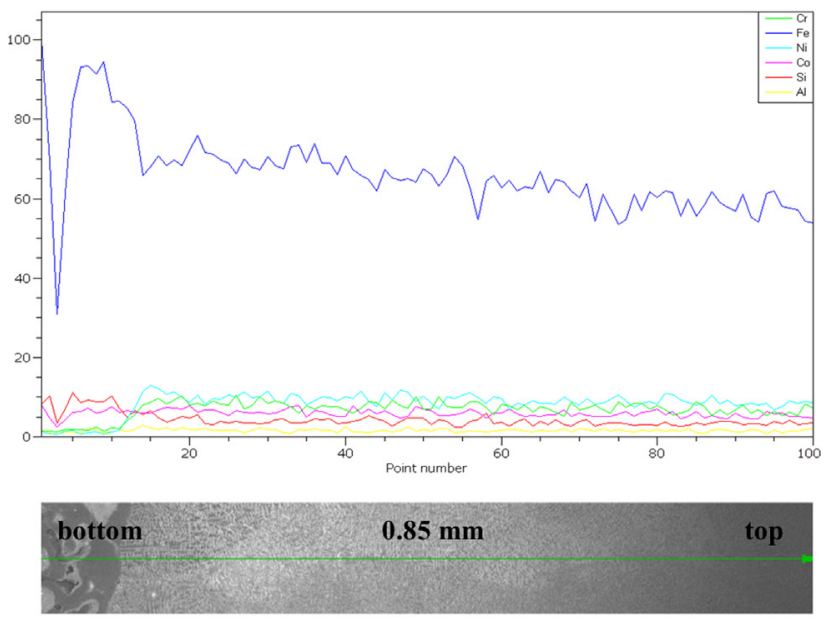

(b)
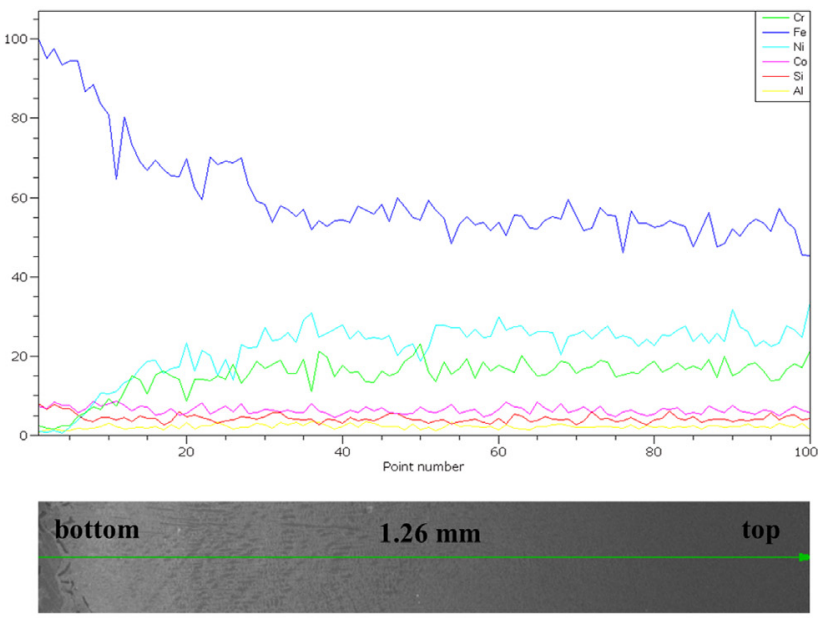

(c)
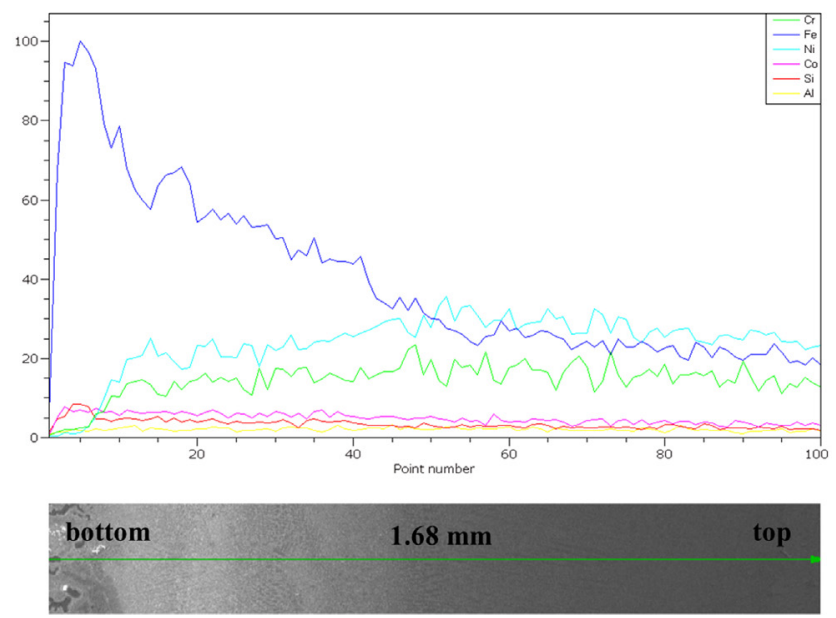

Fig. 11. Line scanning analysis from substrate to coating, (a) Sample L1, (b) Sample L3, (c) Sample L6.

(the content ratio of $\mathrm{Fe}-\mathrm{Ni}$ ) indicated the dilution effect in the local region of the coating caused by the multi-layer deposition (Fig. 11).

As for the coating with six layers (sample L6), the Ni content exceeded the Fe content, which was diluted by the re-melting of adjacent layers. This gradual distribution of elements contributed to the reduction of internal stress induced by the difference of material thermo-physical properties, as well as of the cracking susceptibility at the bonding interface.

\subsection{Microstructure in the bonding zone}

Fig. 12 shows the bonding interface microstructure of the coatings with one, four, and six layers, respectively. Metallurgical bonding between coating and substrate was achieved in all these samples. The bonding line was not smooth, as shown in Fig. 12(a). This can be explained by the diversity of the phases and local inhomogeneous composition in the CGI substrate. Owing to the composition of the CGI substrate being almost eutectic, there was no distinct partial melting region above the HAZ. The microstructure in the HAZ consisted of high carbon martensite $(\mathrm{M})$, undissolved graphite $(\mathrm{G})$, residual austenite (Ar), and a small amount of ledeburite (Ld). These phases were not evenly distributed in the HAZ. The microstructure in the HAZ depends on the heating temperature and cooling rate. High-carbon content martensite was mainly seen in the vicinity of bonding interface. The heating temperature in this region was higher and the increase lasted longer than the other region in the HAZ when the CGI substrate and the powder were irradiated by the laser beam. Consequently, the ferrite and pearlite, the starting microstructure of the CGI substrate transformed into austenite, which immediately transformed into fine high-carbon martensite due to the high cooling rate when the laser beam moved away. The local carbon content increased because of dissolution of the graphite. Due to the low diffusivity, a little ledeburite was formed by eutectic reaction in the vicinity of the undissolved graphite, or in the location where there had previously been graphite present. In regions far from the bonding interface, the martensitic transformation was incomplete due to the low heating temperature, resulting in residual austenite being seen. As the distance from the bonding interface increased, the fraction of martensite decreased, and the fraction of residual austenite and undissolved graphite increased.

The bonding zone was susceptible to cracking owing to its poor plasticity and low toughness of the high carbon martensite, as well as the transformation stress induced by the volume expansion when the martensite formed. This is confirmed by Fig. 12(b), which shows two microcracks measuring $20-30 \mu \mathrm{m}$ near the bonding interface. The zone with martensite present in the microstructure below the bonding interface is defined as the martensitic zone (MZ), which lies between the two yellow dashed lines in Fig. 12. It can be concluded that the brittleness of the bond has a positive correlation with the depth of the MZ, which is about $400 \mu \mathrm{m}$ into the coating with a single layer (sample L1).

The microstructure of the coating with four layers still contained high carbon martensite, undissolved graphite, and ledeburite around it (see Fig. 12(c) and (d)). However, the depth of the MZ decreased to $104 \mu \mathrm{m}$. The same tendency is revealed in Fig. 12(e) and ( $f$ ), which show the microstructure of a coating with six layers. No cracking in the HAZ was found in these two samples (L4 and L6).

The depths of MZ in coatings with various numbers of layers are summarised in Table 4. The depth of the MZ decreased with an increasing number of clad layers. In particular, here was a sharp decline in MZ depth when the third or the fourth layer had been deposited. The MZ depth of the coating with six layers was only about one fifth of that of the single layer coating.

The decrease in $\mathrm{MZ}$ depth is the result of thermal cycling in the multi-layer cladding process, which could change the microstructure of the MZ. Fig. 13 shows the microstructural evolution of the MZ: Fig. 13(a) and (b) are magnified views of the MZ of the coating with a single layer, and four layers, respectively, and were from the same position, the centre of which was about $300 \mu \mathrm{m}$ below the bonding interface. The martensite, and residual austenite, were in a metastable state at room temperature. During the multi- 

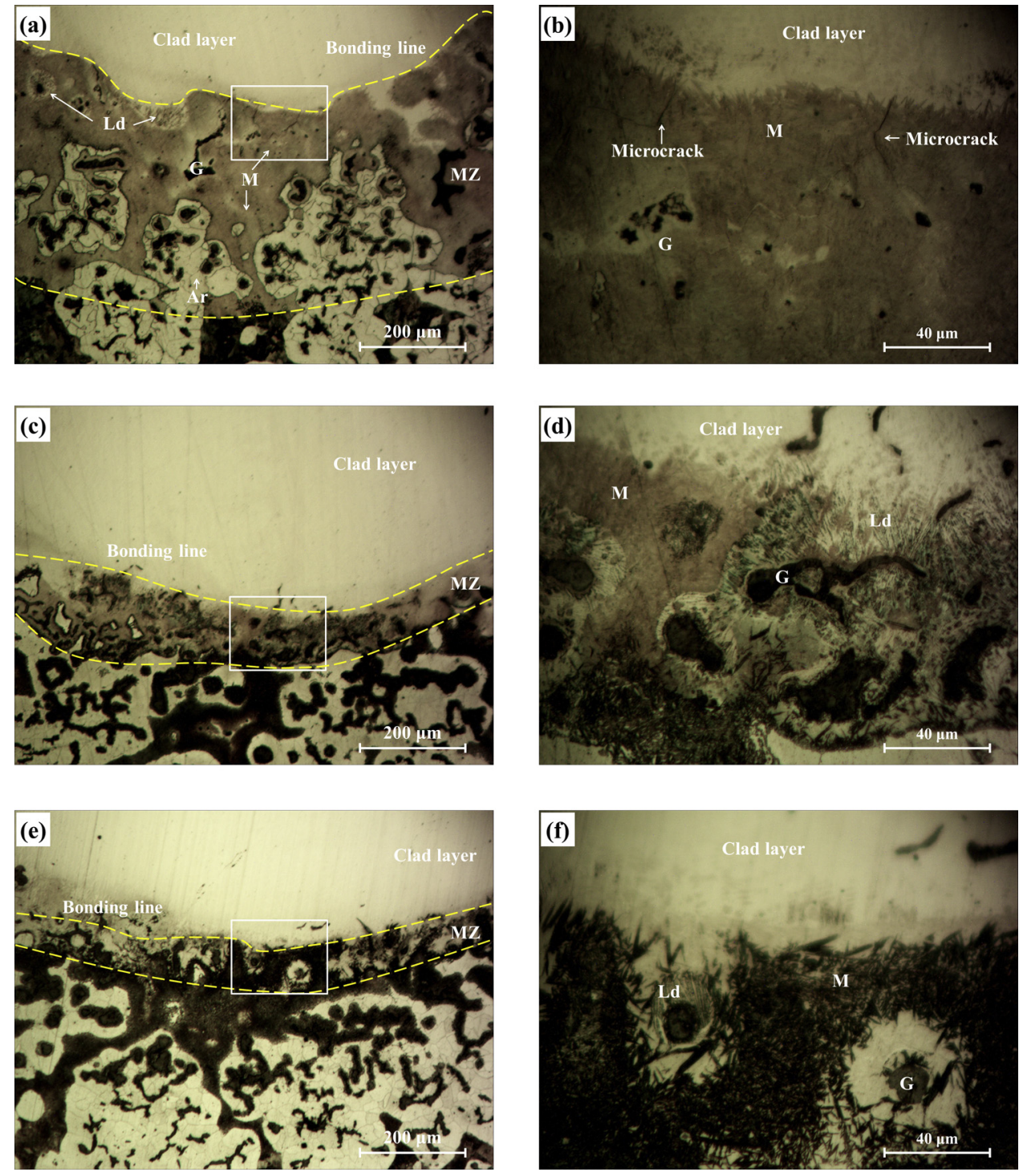

Fig. 12. Microstructure of the cross-section of the bonding interface, (a) (b) one-layer cladding, (c) (d) four-layer cladding, (e) (f) six-layer cladding.

Table 4

The depth of the MZ in the coating cross-section.

\begin{tabular}{|c|c|c|c|c|c|c|}
\hline Sample & L1 & $\mathrm{L} 2$ & L3 & L4 & L5 & L6 \\
\hline Depth of $M Z / \mu \mathrm{m}$ & 400 & 382 & 289 & 104 & 90 & 76 \\
\hline
\end{tabular}
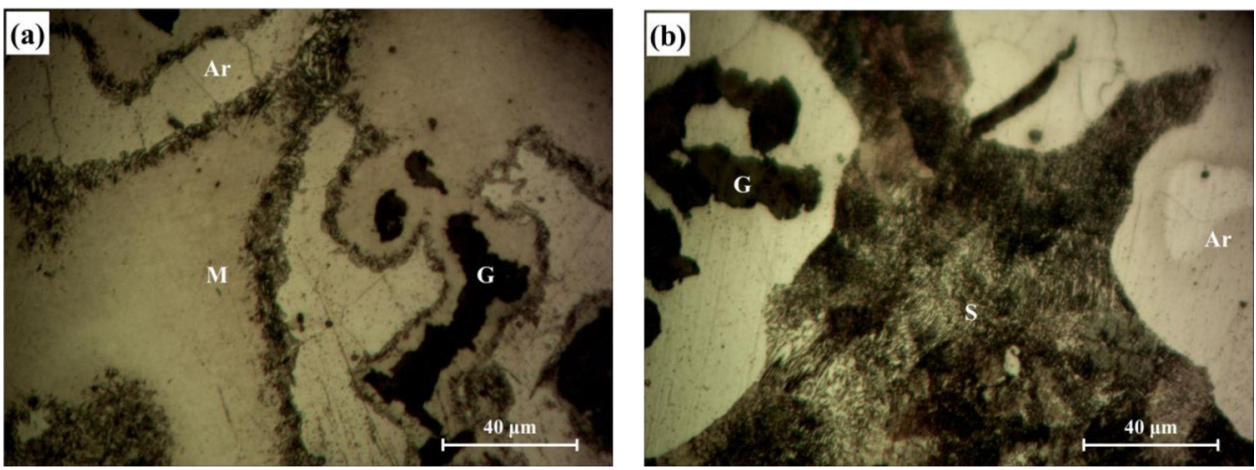

Fig. 13. Microstructure evolution in the martensite zone in multi-layer cladding, (a) one-layer cladding, (b) four-layer cladding. 


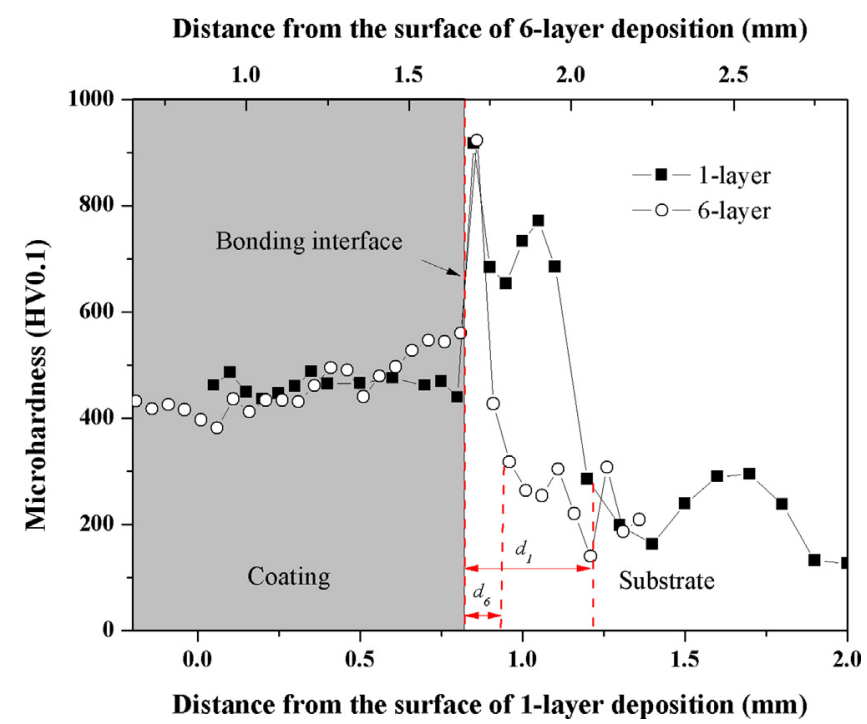

Fig. 14. Micro-hardness profiles of the investigated single, and multi-layer, coatings.

layer cladding process, the substrate temperature rose and the microstructure in the HAZ was reheated with thermal input from deposition of the subsequent layers. The zone far from the bonding interface, as seen from Fig. 13(b), may reach a sufficiently high temperature but remained below the eutectoid line. At this temperature, the carbon dissolved in the martensite was precipitated and the martensite was decomposed, transforming into tempered sorbite, as seen in Fig. 13(b), which indicates the lamellar structure thereof. Tempered sorbite has better plasticity and better toughness than martensite. As a result, the brittleness was improved and the crack susceptibility was reduced. On the other hand, the temperature may breach the eutectoid line near the bonding interface in the deposition of subsequent layers, giving rise to the formation of martensite again. This is why martensite was still found around the bonding interface (see Fig. 12(f)).

\subsection{Micro-hardness}

Micro-hardness is a significant feature that can represent some mechanical properties of the coatings. The micro-hardness profiles along the depth in the cross-section of the coatings with a single layer, and six layers, are shown in Fig. 14. The testing points extended from the coating surface to the CGI substrate. The bonding interfaces were aligned to compare the micro-hardness profiles. As for the single layer coating, the micro-hardness was relatively uniform in the melted zone (indicated in grey) with a mean value of $462 \mathrm{HV} 0.1$. However, the micro-hardness increased to 917HV0.1 around the bonding interface, because of the existence of high carbon martensite and ledeburite contents. The micro-hardness of the CGI substrate fluctuated in the range of 100HV0.1 to 300HV0.1 due to the non-uniform microstructure therein. Therefore, a high micro-hardness zone was found to lie in the profile between the coating and the CGI substrate. The width of the high micro-hardness zone $\left(d_{1}\right)$ was about $400 \mu \mathrm{m}$. The width of the high micro-hardness zone was consistent with the depth of the MZ, as discussed above.

Within the interior of the six layer coating, the micro-hardness dropped slightly from the bonding interface to the coating surface. This can be attributed to the dilution of the multi-layer coating with $\mathrm{C}$ from the CGI substrate, which leads to the decrease of the hard phase (such as $\mathrm{Cr}_{7} \mathrm{C}_{3}$ and $\mathrm{Cr}_{23} \mathrm{C}_{6}$ ) content. Similarly, with the decreasing dilution in multi-layer cladding, the average microhardness of the coating decreased. For the six-layer coating, the average micro-hardness dropped to 441HV0.1. It is worth mention-

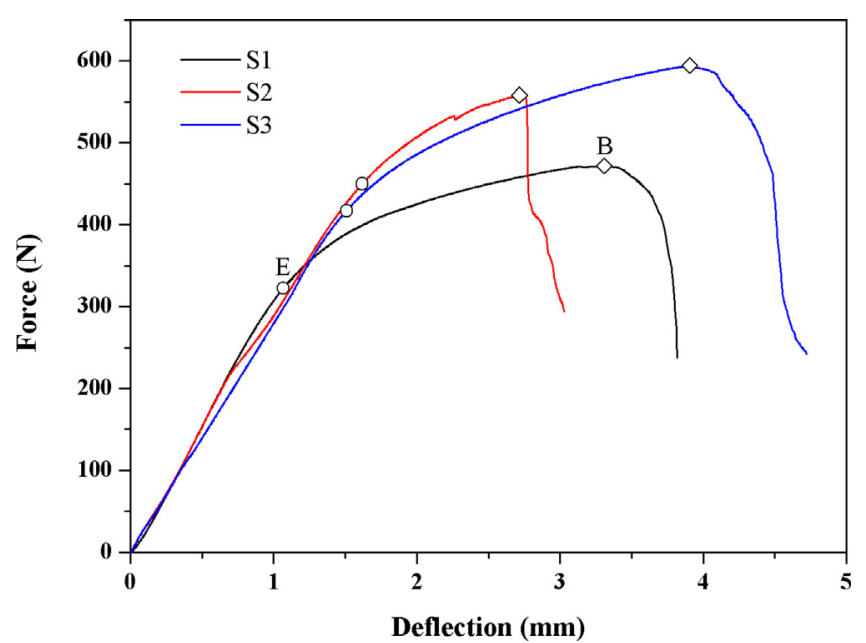

Fig. 15. Load-deflection curves.

ing that the width of the high micro-hardness zone $\left(d_{6}\right)$ decreasd to about $100 \mu \mathrm{m}$. The change in micro-hardness below the bonding interface confirmed aforementioned microstructure in the $M Z$, which revealed the phase transformation from martensite to tempered sorbite caused by thermal cycling during multi-layer laser cladding.

\subsection{Bending test}

In Fig. 15 the load-deflection curves are presented for the uncoated specimen (S1), single clad layer specimen (S2), and multilayer coated specimen (S3). These three plots exhibited similar features, namely, an elastic stage (OE) and a plastic stage (EB). In the elastic stage, the load was linearly proportional to the deflection, indicating linear elastic deformation in this stage of the bending test. The flexural elastic modulus $E_{\mathrm{b}}$ can expressed as:

$E_{\mathrm{b}}=\frac{L_{\mathrm{s}}^{3}}{48 I}\left(\frac{\Delta F}{\Delta f}\right)$

where $L_{\mathrm{S}}$ is the span, $I$ is the second moment of area of the crosssection of the specimen, and $\Delta F$ and $\Delta f$ are increments of load and deflection, respectively. When the bending test continued, the specimen suffered plastic deformation until it broke into two parts at its maximum load (see point B). The bending strength $\sigma_{\mathrm{bb}}$ is defined by

$\sigma_{\mathrm{bb}}=\frac{F_{\mathrm{bb}} L_{s}}{4 W}$

where $F_{\mathrm{bb}}$ is the maximum load and $W$ is the section factor of the specimen. When the specimen fractures, the corresponding deflection is obtained as a fracture deflection $f_{\mathrm{bb}}$. The plastic deflection is defined as the increment of deflection between the elastic limit $\mathrm{E}$ and the break point $\mathrm{B}$ and describes the plasticity of the tested specimen. The mechanical properties of bending test specimens, including bending elastic modulus, bending strength, fracture deflection, and plastic deflection, are summarised in Table 5.

As seen from the load-deflection curve of specimen S1 in Fig. 15, there was a plastic stage, after the elastic stage, and before the uncoated specimen fractured. The plastic deflection reached $2.24 \mathrm{~mm}$, demonstrating the considerable plasticity of the CGI material. The bending elastic moduli of the specimens were close to each other, especially among the two coated specimen (S2 and S3). Yet the elastic limit was slightly enhanced by the coatings over the bare CGI substrate, as shown in Fig. 15. The bending strength of the specimen produced by direct single layer laser cladding was improved. One of the reasons for the improvement in bend- 
Table 5

Bending property of tested specimens.

\begin{tabular}{|c|c|c|c|c|}
\hline Specimen & Bending elastic modulus/GPa & Bending strength/MPa & Fracture deflection $/ \mathrm{mm}$ & Plastic deflection $/ \mathrm{mm}$ \\
\hline $\mathrm{S} 1$ & 63.4 & 707 & 3.31 & 2.24 \\
\hline S2 & 57.6 & 882 & 2.72 & 1.10 \\
\hline S3 & 56.8 & 891 & 3.91 & 2.40 \\
\hline
\end{tabular}

ing strength was that the NiCoCr alloy bestowed the advantage of higher strength over the CGI material, which could be taken as a periodic array of loosely bonded vermicular inclusions in the matrix material. Besides, the epitaxial growth of the multi-layer coating resulted in a microstructure of fine columnar dendrites with strong secondary arms, which might help crack closure and retard crack growth according to Li et al. (2013). Due to the high cooling rate, the grain size of multi-layer coating mainly ranged from $5 \mu \mathrm{m}$ to $10 \mu \mathrm{m}$ (Figs. 7-9), and are much smaller than that of CGI substrate. It was believed that finer grain lead to higher strength. However, both the fracture deflection and plastic deflection of specimen S2 were lower than those of the CGI substrate (S1), indicating the brittleness of the single layer coating on its CGI substrate. The brittleness was believed to be associated with the hard phases and microcracking in the bonding zone formed under the high cooling rate as estimated in Section 3.2. During the loading stage of the bending test, the stress was concentrated on the microcrack tip. As a result, areas close to the bonding interface were prone crack generation. Owing to the low toughness of the martensite and leduburite, cracks propagated and extended easily under shear. These cracks interconnected and extended into the coating and substrate, causing fracture.

On the contrary, the fracture deflection and plastic deflection of the specimen with its coating produced by multi-layer laser cladding (S3) increased to $3.91 \mathrm{~mm}$ and $2.40 \mathrm{~mm}$, respectively, with the bending strength increasing to $891 \mathrm{MPa}$. As can be seen from comparison with the curve for S2 in Fig. 15, it could be inferred that the improvement of the plasticity was due to the microstructural evolution of the bonding interface in multi-layer cladding process, which resulting in the decomposing of martensite and the decrease of depth of MZ. The improved plasticity ensured the highest bending strength of $891 \mathrm{MPa}$ in the three samples. Thus, the improvement of the bending strength was the combined result of the material advantage, the epitaxial growth, the grain refining effect, and the reduced depth of MZ on the bonding zone. The bending test confirmed that the bonding brittleness was reduced and the mechanical properties were improved by use of this multi-layer laser cladding approach.

\section{Conclusions}

The aim of this study was to conduct laser cladding of cast iron to build a well bonded $\mathrm{NiCoCr}$ alloy coating using a multilayer deposition approach instead of preheating. The morphology, microstructure, and micro-hardness of the coatings with their different numbers of layers were analysed by experimental investigation. The following conclusions can be drawn from this research:

(1) With an increasing number of deposited layers, the layer height increased linearly while the width increased slightly. The melt depth was almost constant after the second layer was deposited, which demonstrated that the CGI substrate beneath the bonding interface no longer melted. The dilution declined from $72.5 \%$ of the single layer coating to $42.9 \%$ thereof with a six-layer coating.

(2) The microstructures of coatings with different numbers of layers exhibited fine dendrites surrounded by an inter-dendritic network of precipitates. In multi-layer cladding, the crystallo- graphic structure and dendrite orientation of the pre-deposited layer were reproduced due to epitaxial growth. The carbide precipitates at the inter-dendritic zone changed gradually from lamellar $\mathrm{Fe}_{3} \mathrm{C}$, to small-sized $\mathrm{Cr}_{3} \mathrm{C}_{7}$ and $\mathrm{Cr}_{23} \mathrm{C}_{6}$. The EDS line analysis results demonstrated a gradual distribution of elements through the multi-layer coatings, contributing to the reduction of internal stress and in cracking susceptibility at the bonding interface.

(3) The microstructure in the HAZ consisted of high carbon content martensite, undissolved graphite, residual austenite, and a small amount of ledeburite. Microstructural investigation and micro-hardness testing both revealed that the depth of the $\mathrm{MZ}$, contributing to the brittleness of the bonding zone, decreased as the martensite was transformed into the tempered sorbite during the multi-layer cladding process.

(4) The bending strength of multi-layer coated specimens was improved to $891 \mathrm{MPa}$, which was the combined result of a material advantage, a grain refining effect, and the reduced depth of $\mathrm{MZ}$ on the bonding zone. For laser cladding on a CGI substrate, it was confirmed that the bonding brittleness was reduced and the mechanical properties were improved by use of the proposed multi-layer laser cladding approach.

\section{Acknowledgment}

The author acknowledges the Fundamental Research Funds for the Central Universities (Grant No. 2015QNA35) and the Priority Academic Program Development of Jiangsu Higher Education Institutions (PAPD) for supporting this work.

\section{References}

Alabeedi, K.F., Abboud, J.H., Benyounis, K.Y., 2009. Microstrucure and erosion resistance enhancement of nodular cast iron by laser melting. Wear 266 925-933.

Arabi Jeshvaghani, R., Jaberzadeh, M., Zohdi, H., Shamanian, M., 2014. Microstructural study and wear behavior of ductile iron surface alloyed by Inconel 617. Mater. Des. 54, 491-497.

Benyounis, K.Y., Fakron, O.M.A., Abboud, J.H., Olabi, A.G., Hashmi, M.J.S., 2005. Surface melting of nodular cast iron by Nd-YAG laser and TIG. J. Mater. Process. Technol, 170, 127-132.

Bezencon, C., Schnell, A., Kurz, W., 2003. Epitaxial deposition of MCrAlY coatings on a Ni-base superalloy by laser cladding. Scripta Mater. 49, 705-709.

El Cheikh, H., Courant, B., Branchu, S., Hascoët, J.Y., Guillén, R., 2012a. Analysis and prediction of single laver tracks geometrical characteristics in coaxial laser cladding process. Opt. Lasers Eng. 50, 413-422.

El Cheikh, H., Courant, B., Hascoët, J.-Y., Guillén, R., 2012b. Prediction and analytical description of the single laser track geometry in direct laser fabrication from process parameters and energy balance reasoning. J. Mater. Process. Technol, 212, 1832-1839

Jendrzejewski, R., Śliwiński, G., Krawczuk, M., Ostachowicz, W., 2006. Temperature and stress during laser cladding of double-layer coatings. Surf. Coat. Tech. 201, 3328-3334

Lestan, Z., Milfelner, M., Balic, I., Brezocnik, M., Karabegovic, I., 2013. Laser deposition of Metco 15E: colmony 88 and VIM CRU 20 powders on cast iron and low carbon steel. Int. J. Adv. Manuf. Technol. 66, 2023-2028.

Lin, C.-M., Chandra, A.S., Morales-Rivas, L., Huang, S.-Y., Wu, H.-C., Wu, Y.-E., Tsai, H.-L., 2014. Repair welding of ductile cast iron by laser cladding process: microstructure and mechanical properties. Int. J. Cast Met. Res. 27, 378-383.

Li, Z.Y., Zhao, H.Y., Gu, Y., Zhong, M.L., Zhang, B., Zhang, H.J., Liu, W.J., Ren, Z.Y., Yang, M.J., Lin, H.Q., 2013. Fatigue crack propagation in laser alloyed ductile cast iron surface. J. Laser Appl. 25, 012003.

Ocelík, V., De Oliveira, U., De Boer, M., De Hosson, J.Th.M., 2007. Thick co-based coating on cast iron by side laser cladding: analysis of processing conditions and coating properties. Surf. Coat. Tech. 201, 5875-5883. 
Smurov, I., Doubenskaia, M., Zaitsev, A., 2013. Comprehensive analysis of laser cladding by means of optical diagnostics and numerical simulation. Surf. Coat Technol. 220, 112-121.

Sun, G.F., Zhou, R., Li, P., Feng, A.X., Zhang, Y.K., 2011. Laser surface alloying of C-B-W-Cr powders on nodular cast iron rolls. Surf. Coat. Technol. 205, 2747-2754

Xu, P.Y., Liu, Y.C., Yi, P., Fan, C.F., Li, C.K., 2014. Research on variation and stress status of graphite in laser cladding process of grey cast iron. Mater. Sci. Tech. 30, 1728-1734.

Yan, H., Wang, A.H., Xiong, Z.T., Xu, K.D., Huang, Z.W., 2010. Microstructure and wear resistance of composite layers on a ductile iron with multicarbide by laser surface alloying. Appl. Surf. Sci. 256, 7001-7009.
Yan, S.X., Dong, S.Y., Xu, B.S., Wang, Y.J., Ren, W.B., Fang, J.X., 2014. Carbon diffusions in the NiCuFeBSi alloy layer treated by laser cladding on grey cast iron. Rare Met. Mater. Eng. 43, 2182-2186.

Zheng, B., Zhou, Y., Smugeresky, J.E., Schoenung, J.M., Lavernia, E.J., 2008. Thermal behavior and microstructure evolution during laser deposition with laser-engineered net shaping: part II. Experimental investigation and discussion. Metall. Mater. Trans. A 39, 2237-2245. 